Compass: The Journal of Learning and Teaching at the University of Greenwich Vo1 1 (2009)

\title{
Teaching information skills for legal method
}

\author{
Sarah Crofts
}

Information \& Library Services

I have been involved with teaching information skills as part of the Law Department's 1st year Legal Method course since 2000. These sessions have developed from a set of half hour sessions offered on a drop-in basis in 2000 , to the current format of four seminars of an hour each. The four seminars deal with searching the library catalogue; searching the law databases for cases and statutes; searching for journal articles; and finding and evaluating material for law on the free internet.

There are 10 seminar groups for Legal Method so each library seminar is delivered 10 times in the week. The aim of this article is to provide a snapshot of the seminars on journals from January 2009, which I hope will prove interesting to colleagues as an example of services provided by the academic services librarians.

\section{Resources used}

I have been using WebCT to provide blended learning since 2005 and for workshops I tend to use a mix of PowerPoint presentation, WebCT tools such as quizzes, self-tests and discussion lists, as well as discussion and hands-on searching. I also include material in the WebCT Legal Method course to which students can return later if they wish.

One advantage of using the WebCT tools is that students are more easily engaged by activities such as the quizzes. The main disadvantage is in the reliability of the system, which is why I find it invaluable to have a PowerPoint presentation ready to use in the event of the internet being unavailable. The first seminar group is at 9am on a Monday morning and occasionally the internet, portal and WebCT have not been available.

\section{Programme for the Journals Seminar}

The programme consisted of the following:

\section{What are journals?}

This was a short discussion in which I asked students for their ideas as to why journals might be useful in addition to books. Although some groups were more forthcoming than others, most came up with at least two key reasons for using journals, such as currency and their importance as a means of disseminating research. After the seminars, I summarised these contributions and added them to WebCT for the students to refer to again if they wished.

\section{Understanding citations and legal abbreviations}

This was an explanation of how citations are formulated with some examples of different styles. Law students face the additional challenge of having to decipher legal abbreviations so that they can search for the item. Some of these abbreviations are very similar and therefore, a perennial cause of confusion, for example: 'Med LR' is the Medical Law Reports but 'Med.LRev.' is the Medical Law Review. Most students find this aspect of legal research rather boring, but I hoped that the online test 
would help make the topic more interesting, as well as providing an opportunity to practice searching for abbreviations. For this quiz, I used a WebCT 'short answer' self-test with unlimited duration together with the Cardiff University's Cardiff index to abbreviations tool, available at www.

legalabbrevs.cardiff.ac.uk.

\section{Searching for journals and journal articles}

During this part of the session, I reminded students how to search for journals on the library catalogue, as this is an area which often causes confusion - students often try to search by article title rather than by journal title. Another online quiz followed to test the students' understanding for which I used a WebCT 'fill in the blank' self-test.

\section{Planning the search}

During this part of the seminar, I gave students hints for planning their search. This covered concepts such as: analysing the question or topic to pick out key words, how to broaden or narrow the search, using connectors. Most students use search engines such as Google where any type of search will produce results; the library databases to which we have access require a structured approach and it can be quite challenging explaining the significance of this to students (see 'Challenges and problems').

\section{Practical search}

For the final part of the seminar students had the opportunity to search for an article for their English legal system seminar the following week. The students had to choose an article from a legal academic journal on one of the following topics: religious freedom, the Denbigh High School case or the issue of qualified rights under the European Convention of Human Rights. Having found a suitable article, the rest of the task (to be completed after the seminar) was to prepare a presentation setting out the following:

- The name of the article, the author and the citation

- A summary of the content of the article

- An explanation of the viewpoint of the author

- Whether the student agreed or disagreed with the author and the reason

- The reason why the student found the article interesting.

Despite my emphasis on the importance of using keywords and not just cutting and pasting the essay title into the database, nearly everyone did just that, so there is more work to do here! In addition to improving their search skills, this task tested the students' ability to identify articles from academic journals, something which we touched on in the initial 'What are journals?' discussion.

I had also prepared a third activity 'Finding an article from a reference', using the WebCT 'short answer' format. There was not enough time to include this, but it would have tested students' ability to find an article on a database given the citation.

\section{Challenges and problems}

This was the third in the series of library seminars and the size of the groups was becoming less of a problem, as the student numbers had dwindled since the previous seminars. One of the seminar groups started off at the beginning of the year with 30 plus students, but by the January seminar this had fallen to 18 students. There is room for 20 students in the room and I find that optimum 
group size is around 15. Students' behaviour was a problem in only one of the groups with some students who talked throughout.

As always, there were quite a range of abilities with some racing ahead on the self tests while others could not work out what to do.

Despite testing the activities beforehand, there were the inevitable few minor errors in the self-tests which I put right as the week progressed. However, as one of the tutors observed, there might well be errors in real life examples of citations.

One of the biggest challenges concerns the students' 'digital literacy'. I imagine that students' unquestioning use of Google is a challenge faced throughout the university. Although many students do not appear to have the skills to evaluate the sources retrieved from Google, it is perhaps understandable that they prefer the Google interface to many library databases and catalogues. It is beautifully simple and always provides results. A British Library/Centre for Information Behaviour and the Evaluation of Research (CIBER) report (2008) noted that many students do not find library databases easy to use and prefer the familiarity of Google.

This question of students' lack of effective search skills is an issue faced in many Schools. I wonder if there are ways in which the university community could integrate an approach that could improve students' performance of this key research skill. One approach includes the Progression in Information Skills online learning skills modules, which are available to all students and staff of the university, as well as the recently developed Progression for All, for anyone without a university user name and password, available at www.gre.ac.uk/offices/ils/ls/projects/progression.

In addition, the university has been participating in a Higher Education Change Academy project, Developing an institutional model for embedding academic and transferable skills, which began in April 2009. During this, a cross-university team investigated the concept of embedding these skills in university curricula. One of the benefits to students would be the development of information literacy, which provides them with the means to make appropriate judgements about the value and potential uses of different types of material and media, visit www.heacademy.ac.uk/changeacademy.

Finally, there is the issue of 'user-friendliness'. Although I have been using WebCT for some years, it now seems rather cumbersome compared with other tools and Web 2.0 resources which have appeared over the years. Students are so familiar with the look of resources such as Facebook and other social media that WebCT probably looks rather old fashioned in comparison.

\section{Assessment}

The legal method library seminars include assessments which form part of the students' overall assessment for the course. I use a mixture of WebCT multiple choice question assessments with a deadline as well as other types of assessment.

We are lucky enough to have the services of a Lexis Student Associate and a Westlaw student representative both trained and paid by LexisNexis Butterworths and Westlaw.

The Westlaw student representative offered an alternative assessment, in the form of a Westlaw session to which students were asked to sign up. WebCT does not seem to provide a tool for this, so I used the free 'We join in' tool, available at www.wejoinin.com. 


\section{Feedback}

The students' learning logs included some very positive comments about the seminar as follows:

'The use of the journals that we were able to select in the class was useful as I have not seen a law journal before. I really enjoyed going through citations. It was very useful, as the citations for bibliographies and journals are completely different.'

'Before this seminar I had no clear understanding how to read a journal, to look up a journal on LexisNexis or the other websites stated in the seminar. So I felt this seminar really helped me as it has also helped me with the research for the current essay I am writing now for Foundations of Criminology.'

'I was impressed by how easy it was to find relevant sources and think that this is going to assist my studies considerably'

'This seminar was in the library as we learnt how to find journals and abbreviations, etc. It was very useful as we needed it in order to do our work for ELS'

'I find the library seminars useful. This is because we are shown how to use the online sources in order to find cases and journals. Cases and journals are essential for the other courses that we are attending. Also, when I am at home and I am unable to reach a library I feel at ease to know that I can use the online sources. Another thing that I find useful is that we are shown the correct way to input cases and how to abbreviate statutes and so on.'

\section{Conclusion}

The work I do with students is made more effective through close collaboration with, and support by, colleagues in the Law Department, who assist by suggesting topics that they will be covering in the students' other courses such as English Legal System. This ensures that the students recognise a relevance to the seminars which I hope makes it more meaningful for them.

I think it would be useful to learn more about how colleagues in other Schools integrate with their library services, and if there is scope for a cross-disciplinary approach to some of the common challenges students face in terms of information literacy. Even within Information \& Library Services it can be difficult to share good practice with colleagues who are engaged in teaching students and this may also be the case for academic colleagues. A recent JISC report (2009) notes that, although they found much good practice amongst academic and library and computing staff, 'staff are still operating in relative isolation from one another, in many cases, even within their own departments'. I have offered this case study in the hope that it might channel some discussion and debate in the university, and to start the process of sharing information beyond the 'bubble' in which we tend to operate academically.

\section{Note}


This is an example of just one information skills seminar for law. If you would like to find out more or make contact with your academic services librarian, please visit www.gre.ac.uk/offices/ils/ls/ services/asl.

\section{References}

Centre for Information Behaviour and the Evaluation of Research (CIBER) (2008) Information Behaviour of the Researcher of the Future. Online. Available at www.jisc.ac.uk/whatwedo/

programmes/resourcediscovery/googlegen.aspx, (accessed 10 November 2009). London: CIBER.

JISC (2009) Learning Literacies in a Digital Age. Available at www.jisc.ac.uk/publications/ documents/learningliteraciesbp (accessed 10 November 2009). London: JISC Online. 